\title{
The Coyote Lure Operative Device revisited: A fresh look at an old idea
}

\author{
by Are R. Berentsen, Robert M. Timm \\ and Robert H. Schmidt
}

We field-tested the Coyote Lure Operative Device (CLOD), a bait delivery system for coyotes originally conceived by UC Davis researchers in the 1980s. Our objectives were to determine whether free-ranging coyotes would activate CLODs repeatedly when exposed to them over a 12-month period, and whether CLOD activations varied by season. We placed CLODs in pastures with a history of chronic sheep depredation at the UC Hopland Research and Extension Center in Mendocino County. Free-ranging coyotes activated the CLODs repeatedly, but more CLODs were activated during the winter months than at other times of the year. Our study suggests that the CLOD has the potential to become an important tool for managing coyote predation on livestock when used to deliver contraceptive or predacide baits.

$\mathrm{P}_{\mathrm{s}}^{\mathrm{rat}}$ redators killed an estimated 224,200 sheep and lambs nationwide in 2004, costing livestock producers an estimated \$18.3 million (NASS 2005b). As livestock depredation continues to rise, the livestock industry faces the same old dilemma: how to stop predators, primarily coyotes (Canis latrans), from killing livestock. In 2004, 135,600 sheep and lambs were reported lost to coyotes alone, representing $60 \%$ of losses due to all predator types and a financial loss of about $\$ 10.7$ million (NASS 2005b).

While the total losses may not seem overwhelming, they are not distributed evenly across all livestock producers. Because of where they are located, some producers sustain such heavy predation that they cannot operate profitably. Sheep inventories have declined in
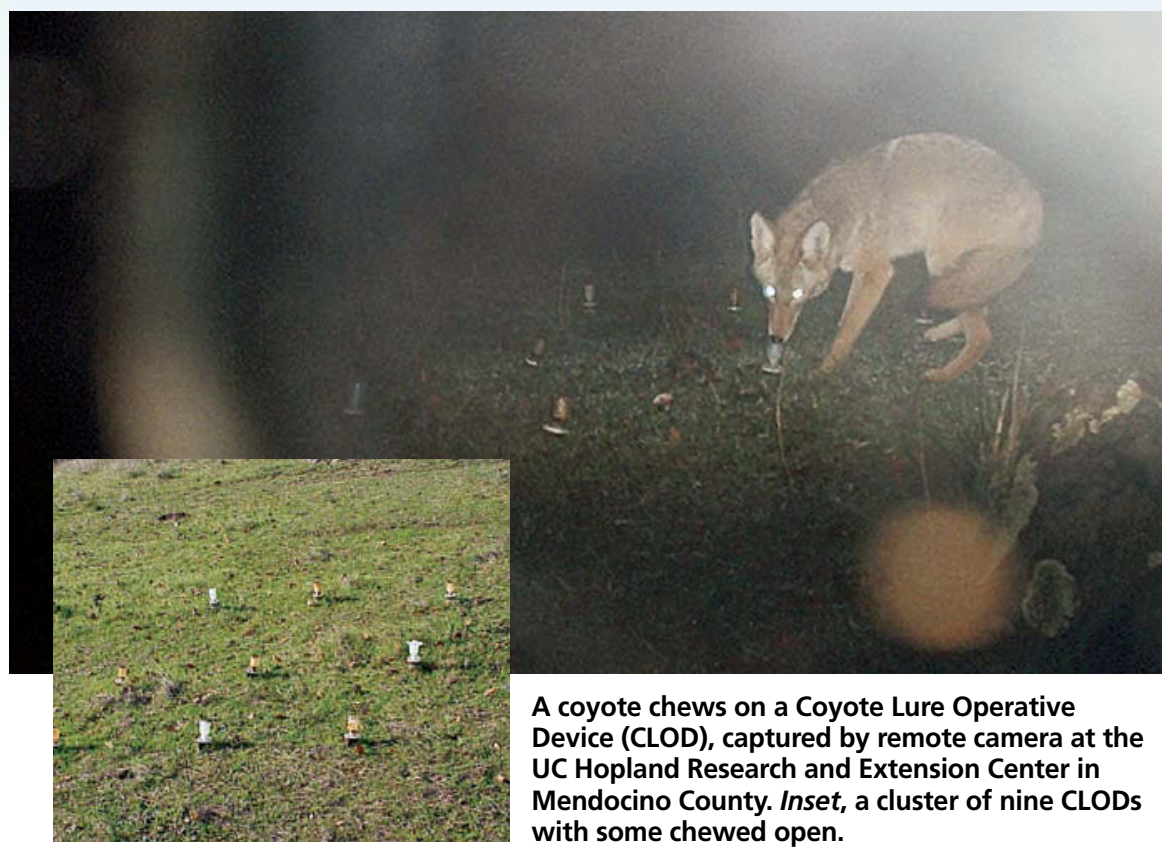

California in recent decades, from 1.12 million in 1994 (NASS 1995) to 680,000 in 2004 (NASS 2005a), as they have nationwide. In 1942, sheep and lamb inventories were approximately 56.2 million head (NASS 2000) whereas 2004 inventories were just over $6.1 \mathrm{mil}-$ lion. Nonetheless, the total number of breeding ewes in California remains second nationwide $(680,000$ head), following only Texas (1.1 million head) (NASS 2005a).

In California, an added complication to coyote control is the 1998 ban on leghold traps and certain toxicants (such as predacides, chemical compounds used to kill predators). These have traditionally been among the most important tools used by livestock producers and predator management professionals to control problem coyotes. In recent years, similar trap or toxicant bans have been enacted in several other states with significant urban populations (Minnis 1998). This has prompted researchers to investigate new methods of predator management as well as to revisit older ideas.

\section{Coyote Lure Operative Device}

Marsh et al. (1982) at UC Davis first conceived the Coyote Lure Operative Device (CLOD) as a tool to deliver chemical agents - such as toxicants, contraceptives or pharmaceuticals - to targeted coyotes. The current model, adapted in large part from Marsh et al. (1982), consists of a 1-ounce plastic vial with a rigid nylon core that is collectively called the "unit head." The unit head is attached by a nylon wing nut to a steel stake anchored into the ground. Because coyotes like sweet-tasting compounds (Mason and McConnell 1997), the unit head is filled with a corn syrup and powdered-sugar mixture (Ebbert 1988). In addition, a commercial coyote attractant designed to elicit biting is applied to the outside of the unit head. Coyotes activate the CLOD by chewing it open and ingesting the contents. After they first ingest the contents of the CLOD, the sweet reward encourages repeat visits (Barnum et al. 1982; Berentsen et al. 2006).

Previous research at the UC Hopland Research and Extension Center (HREC) has shown that paired (male and female), territorial coyotes were responsible for the majority of lamb losses (Jaeger et al. 2001). These older, dominant (alpha) animals are notoriously difficult to target and remove using traditional control tools and methods (Sacks et al. 1999; Windberg and Knowlton 1990). 


\section{CLODs hold the potential to be a selective, efficient tool for managing coyote predation.}

We theorized that coyotes could be conditioned to activate CLODs by filling them with a placebo corn syrup solution and then placing them in areas of high coyote activity or pastures with traditionally high livestock losses. Once frequent or regular activation of CLODs was taking place, it would then be possible to add an approved toxicant to the sweet mixture if and when predation began to occur.

In November 1998, California voters passed a ballot initiative banning the use of the two toxicants that were then registered for use in coyote control, sodium cyanide and Compound 1080. Currently, researchers at the U.S. Department of Agriculture's National Wildlife Research Center are pursuing the development of a new toxicant for coyotes, which could be delivered via the CLOD. Initial research suggests that this toxicant is selective for canids and may be more humane than earlier coyote toxicants (Johnston 2005).

Alternatively, the CLOD could be used to deliver a chemical sterilant to prevent coyote reproduction. In studies of coyotes in the intermountain West, the surgical sterilization of coyotes dramatically curtailed livestock depredation (Bromley and Gese 2001). Moreover, Buseck (2004) successfully used the CLOD to deliver oral contraceptive agents to captive coyotes. Research to find an effective coyote sterilant that can be successfully delivered orally to wild coyotes is currently in progress at several facilities.

The objectives of our research were to determine whether free-ranging
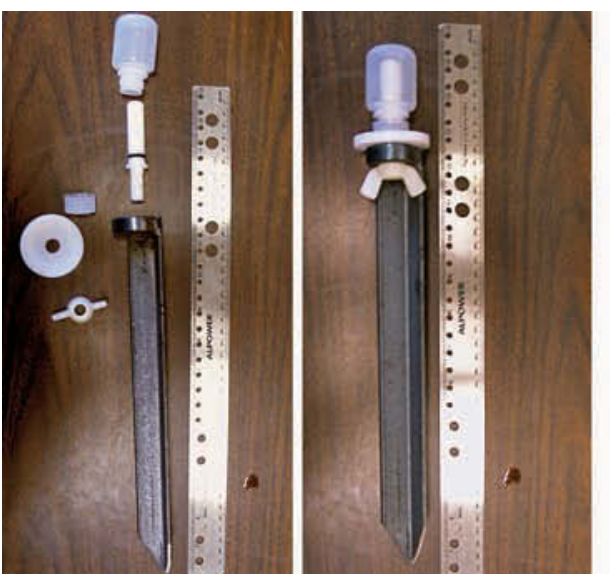

Left, a disassembled CLOD with individual components. Right, the current model of the CLOD, fully assembled. coyotes would activate CLODs repeatedly, and whether the frequency of activation would change throughout the year. Berentsen et al. (2006) found that captive coyotes would approach and activate CLODs, somewhat warily upon first exposure, but then quickly and repeatedly when exposed to them daily over a 4-day test period. In previous research, free-ranging coyotes activated CLODs at approximately the same rate as M-44 sodium cyanide ejectors (Ebbert 1988), when both devices were placed in a typical rangeland environment. In addition to testing CLOD activation, we used remote cameras to photograph animals that investigated and activated CLODs. Photographs were also used as a reference to identify whether the same or different coyotes were approaching and activating the CLODs.

\section{Attracting coyotes to CLODs}

HREC is a working sheep ranch in Mendocino County, which maintains a large flock of sheep and lambs yearround (700 to 1,500 head) and suffers high levels of predation by coyotes (Scrivner et al. 1985). This facility has been the site of coyote research for more than 30 years and was the location of some of the early CLOD research (Timm and Vaughn 2003). Coyote control is actively conducted at HREC to protect the research sheep flock, but lethal coyote removal was temporarily suspended during this study. (Coyotes are normally shot by on-site personnel, and state wildlife services specialists perform some snaring.)
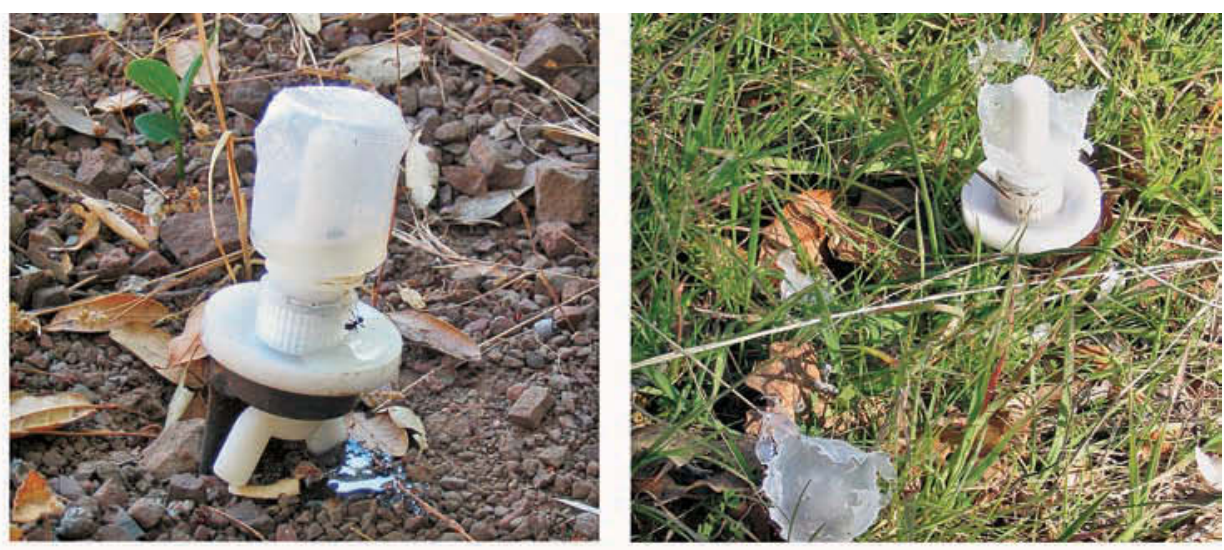

CLODs chewed by, left, an opossum and, right, a coyote. The devices contain a sweet-tasting mixture plus a commercial attractant or scent. Once coyotes are habituated to consuming the CLOD's contents, wildlife managers can add toxicants or sterilants to control problem animals and protect livestock.
To tag coyotes, we captured them using wire snares that had been modified to prevent mortalities. Snares were checked daily in the morning. Captured coyotes were fitted with color-coded leather collars and numbered ear tags. Capture efforts were conducted from June 2004 through May 2005.

During this period, we also placed CLODs along roads and trails frequented by coyotes as well as in pastures with a history of sheep predation. Four remote cameras (Trailmac, Trailsense Engineering, Middletown, Del.) were placed at clusters of six to nine CLODs. The CLODs were checked twice every week and the cameras were checked weekly. Based on the recommendations of professional trappers and previous research, we used the following three commercial coyote attractants / scents in the study: Powder River (PR), Government Call (GC) and Subdued (SD) (O'Gormans, Broadus, Mont.). A synthetic attractant called Fatty Acid Scent (FAS) (Pocatello Supply Depot, Pocatello, Ind.) was added during winter months and was used continuously for the duration of the study (table 1). During the fall and winter, attractants were applied to the CLODs via a mixture of melted paraffin, in order to decrease volatilization of the lures and reduce the potential for rain to wash the attractants away.

\section{Use peaks in winter}

We captured, marked and released 16 coyotes. Half were female and half were male, and most were yearlings. 


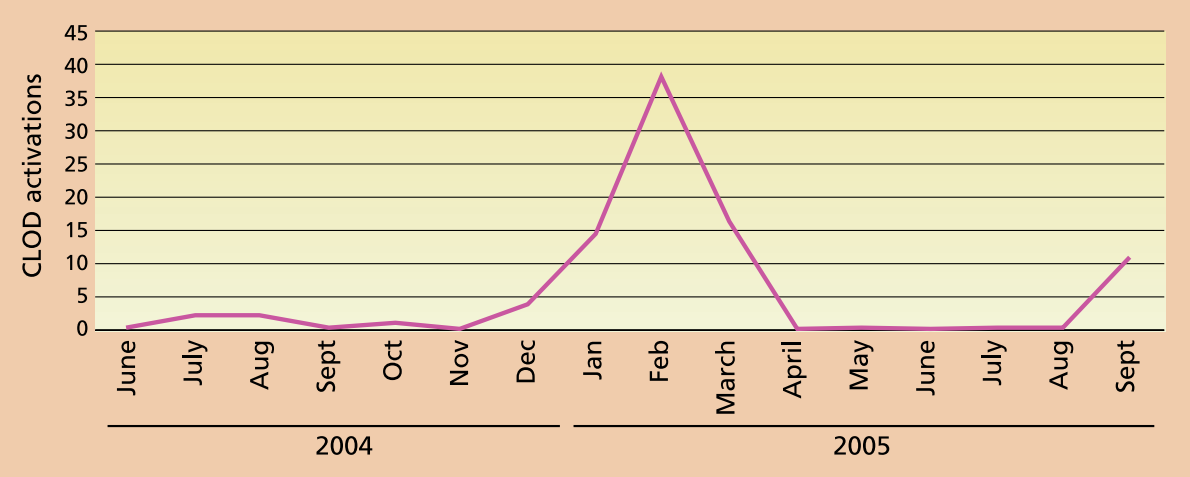

Fig. 1. Number of CLODs activated by coyotes, June 2004 to September 2005.

Twelve of the coyotes were captured between October 2004 and March 2005. One was recaptured and several others were subsequently sighted at HREC and adjacent properties.

While we did not photograph any marked coyotes approaching or activating the CLODs, we did take four photographs of three different coyotes. Other species photographed approaching the CLODs included sheep, deer, turkey vultures, wild turkeys, opossums, skunks, bobcats, cattle, raccoons and domestic dogs. Besides coyotes, opossums were the only animals photographed chewing on CLODs. The CLODs activated by coyotes were typically chewed open at the top, with little or none of the corn syrup mixture remaining; those chewed by opossums were covered with small holes, which allowed the contents to drain onto the ground.

From June 2004 through September 2005 , coyotes activated 88 CLODs. Of these, 29 were scented with FAS, 55 with GC and two each of SD and PR (table 1). Altogether, there were only nine CLOD activations by coyotes during the first 7 months of the study: two in July, two in August, one in October and four in December 2004.

In contrast, many more CLODs were activated during the next 3 months of the study (fig. 1). Coyotes activated 68 CLODs from January through March 2005. In addition, CLODs were activated by coyotes on a weekly basis at two locations. Sheep actively grazed one location, and the other was more remote and ungrazed. Several miles separated these pastures, making it unlikely the same coyote was activating CLODs in both locations. It is possible that the CLODs had been placed along a territorial boundary and that activation was taking place during "perimeter patrols." It is also possible that coyotes trespassing from a neighboring territory were activating the CLODs, similar to Windberg and Knowlton's (1990) finding that coyotes are more likely to be trapped while trespassing than in their own territory.

After March, coyote CLOD activation dropped again. No CLODs were activated from April through August, and 11 CLODs were activated in September. During the peak CLOD activation period (January through March), GC and FAS were the only two attractants used. Roughly half of each type was activated: 20 of the 44 FAS-scented CLODs, and 48 of the 88 GC-scented CLODs.

Because CLOD activations peaked from January through March, we theorize that there may be a seasonal pattern to activation as a result of increased coyote movement, the attractants used or seasonal behavioral changes. Sodium cyanide ejector devices (M-44s), which have been used by predator control professionals for decades and employ odor attractants to stimulate coyote activation, are known to be most successful during cooler months of the year (Phillips and Nunley 1995). The summer drop-off in activations occurred even when coyotes had already learned that a sweet reward was available in the CLODs.

\section{Coyote-selective devices}

Our data suggests that CLODs with both FAS and GC were activated in proportion to their availability during the winter and early spring, when activations peaked. In some cases where clusters and transects of CLODs contained both FAS and GC scents, there appeared to be a bias toward FAS. For example, in a cluster of nine CLODs containing six scented with GC and three with FAS, all three FAS-scented CLODs were activated but none of the six GC-scented CLODs were chewed.

We determined that free-ranging coyotes will activate CLODs repeatedly. DNA obtained from two chewed CLODs at HREC determined that the

\begin{tabular}{|c|c|c|c|c|c|c|c|c|}
\hline \multirow[b]{2}{*}{ Month } & \multicolumn{2}{|c|}{ Government Call } & \multicolumn{2}{|c|}{ Fatty Acid Scent } & \multicolumn{2}{|c|}{ Subdued } & \multicolumn{2}{|c|}{ Powder River } \\
\hline & $\begin{array}{c}\text { In } \\
\text { place }\end{array}$ & Activated & $\begin{array}{c}\text { In } \\
\text { place }\end{array}$ & Activated & $\begin{array}{c}\text { In } \\
\text { place }\end{array}$ & Activated & $\begin{array}{c}\text { In } \\
\text { place }\end{array}$ & Activated \\
\hline June 2004 & 0 & 0 & 0 & 0 & 0 & 0 & 99 & 0 \\
\hline July 2004 & 67 & 2 & 0 & 0 & 7 & 0 & 26 & 0 \\
\hline Aug 2004 & 79 & 0 & 0 & 0 & 30 & 2 & 29 & 0 \\
\hline Sept 2004 & 79 & 0 & 0 & 0 & 30 & 0 & 29 & 0 \\
\hline Oct 2004 & 79 & 0 & 0 & 0 & 31 & 0 & 29 & 1 \\
\hline Nov 2004 & 79 & 0 & 0 & 0 & 31 & 0 & 29 & 0 \\
\hline Dec 2004 & 79 & 0 & 31 & 3 & 0 & 0 & 29 & 1 \\
\hline Jan 2005 & 88 & 14 & 39 & 0 & 0 & 0 & 0 & 0 \\
\hline Feb 2005 & 85 & 28 & 44 & 10 & 0 & 0 & 0 & 0 \\
\hline March 2005 & 85 & 6 & 45 & 10 & 0 & 0 & 0 & 0 \\
\hline April 2005 & 69 & 0 & 69 & 0 & 0 & 0 & 0 & 0 \\
\hline May 2005 & 69 & 0 & 69 & 0 & 0 & 0 & 0 & 0 \\
\hline June 2005 & 69 & 0 & 69 & 0 & 0 & 0 & 0 & 0 \\
\hline July 2005 & 69 & 0 & 69 & 0 & 0 & 0 & 0 & 0 \\
\hline Aug 2005 & 69 & 0 & 69 & 0 & 0 & 0 & 0 & 0 \\
\hline Sept 2005 & 69 & 5 & 69 & 6 & 0 & 0 & 0 & 0 \\
\hline \multicolumn{2}{|c|}{ Total activations } & 55 & & 29 & & 2 & & 2 \\
\hline
\end{tabular}


same yearling male was responsible for both activations. In addition, DNA analysis from CLODs activated at Antelope Island State Park, Utah, during a concurrent study also showed that individual coyotes will activate CLODs repeatedly, but these activations also exhibited seasonal differences (Berentsen 2005, unpublished data). These results suggest that attracting the same coyote to CLODs is possible, but further research is warranted to achieve activation year-round.

Most of the coyotes that we marked were not alpha (territorial) coyotes, and only unmarked individuals were photographed. We had hoped to obtain more photographs of coyotes activating the CLODs, but remote photography is challenging due to the dispersed nature of CLODs when deployed, the cost of camera equipment and the natural wariness of coyotes, especially an alpha pair, toward novel objects. Other researchers have noted that adult dominant coyotes are very difficult to photograph via remote cameras, even in locations where coyotes have not been subjected to control efforts (Sequin et al. 2003). However, our remote cameras provided valuable information about the nontarget species investigating CLODs; they could be a useful tool in future research on nontarget species that investigate bait delivery devices or bait stations. Remote photography indicated that at HREC, we must be attentive to the potential for opossums (a nontarget species) to consume CLOD contents.

Our research suggests that coyotes continue to demonstrate seasonal preferences toward attractants, even when the CLOD offers a sucrose syrup reward year-round. However, coyotes will consume the CLOD contents and multiple CLOD activations are possible, albeit seasonally. Further investigation of various odor attractants and food rewards may enhance the visitation and activation of CLODs by coyotes. While we could not determine whether CLODs would be activated repeatedly by the same free-ranging coyotes, our work with captive coyotes makes us believe that this is so. CLODs hold the potential to be a selective, efficient tool
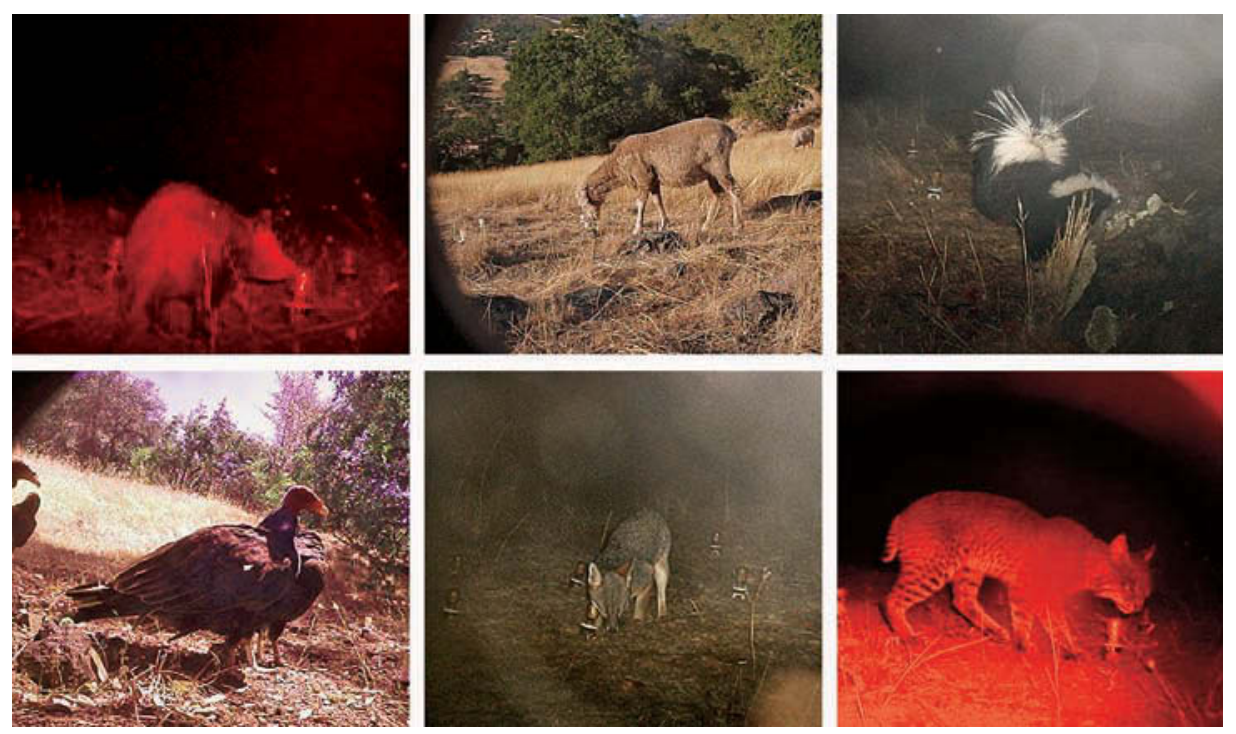

Clockwise from upper left, visitors to the CLODs included an opossum, sheep, skunk, bobcat, coyote and turkey vulture.

for managing coyote predation when used to deliver toxicants or contraceptive agents. While CLODs will not be a panacea for coyote conflicts with humans and livestock, they may become a useful addition to the dwindling number of tools currently available to landowners and predator management professionals.

A.R. Berentsen is Research Associate, Department of Forest, Range and Wildlife Sciences, Utah State University, Logan; R.M. Timm is Superintendent and Cooperative Extension Specialist, UC Hopland Research and Extension Center; and R.H. Schmidt is Associate Professor, Department of Environment and Society, Utah State University, Logan. Funding was provided by the California Department of Food and Agriculture Vertebrate Pest Control Research Advisory Committee, contract 03-0325. The authors thank John Hays, Jr., Jennifer Smith and Gary Johnson for assistance in the field, and two anonymous reviewers for providing helpful comments and suggestions.

\section{References}

Barnum DA, Fagre DB, Marsh RE. 1982. Hopland tests of bait delivery devices. Proc Ann Meeting West Reg Coord Comm 26, Waco, TX. p 14-6.

Berentsen AR, Schmidt RH, Timm RM. 2006. Repeated exposure of coyotes to the Coyote Lure Operative Device. Wildl Soc Bull 34(3):809-14.

Bromley C, Gese EM. 2001. Surgical sterilization as a method of reducing coyote predation on domestic sheep. J Wildlife Manage 65(3):510-9.

Buseck RS. 2004. Development of a coyote (Canis latrans) specific delivery system for oral contraceptives. MS thesis, University of Wyoming, Laramie.

Ebbert SM. 1988. Field evaluation and improvement of a new system for delivering substances to coyotes. MS thesis, Texas A\&M University, College Station.
Jaeger MM, Blejwas KM, Sacks BN, et al. 2001. Targeting alphas can make coyote control more effective and socially acceptable. Cal Ag 55(6):32-6.

Johnston JJ. 2005. Evaluation of cocoa and coffee derived methylxanthines as a toxicant for control of predatory coyotes. J Agric Food Chem 53:4069-75.

Marsh RE, Howard WE, McKenna SM, et al. 1982. A new system for delivery of predacides or other active ingredients for coyote management. Proc Vertebr Pest Conf 10:229-33

Mason JR, McConnell JE. 1997. Hedonic responses of coyotes to 15 aqueous taste solutions. J Wildl Res 2:21-4

Minnis DL. 1998. Wildlife policy-making by the electorate: An overview of citizen-sponsored ballot measures on hunting and trapping. Wildl Soc Bull 26(1):75-83.

NASS [National Agricultural Statistics Service]. 1995. Sheep and goats. US Department of Agriculture, Washington, DC. 14 p (document released Jan. 27, 1995).

NASS. 2000. Sheep and goats. US Department of Agriculture, Washington, DC. $14 \mathrm{p}$ (document released Jan. 28, 2000)

NASS. 2005a. Sheep and goats. US Department of Agriculture, Washington, DC. $15 \mathrm{p}$ (document released Jan. 28, 2005)

NASS. 2005b. Sheep and goats death loss. US Department of Agriculture, Washington, DC. 11 p (document released May 6, 2005).

Phillips RL, Nunley GL. 1995. Historical perspective on coyote control methods in Texas. In: Coyotes in the Southwest: A Compendium of our Knowledge. Texas Parks and Wildlife Department, San Angelo. p 148-57.

Sacks BN, Blejwas KM, Jaeger MM. 1999. Relative vulnerability of coyotes to removal methods on a Northern California ranch. J Wildl Manage 63(3):939-49.

Scrivner JH, Howard WE, Murphy AH, Hays JR. 1985. Sheep losses to predators on a California range, 1973-1983. J Range Manage 38(5):418-21.

Sequin ES, Jaeger MM, Brussard PF, Barrett RH. 2003. Wariness of coyotes to camera traps relative to social status and territory boundaries. Can J Zool 81:2015-25

Timm RM, Vaughn CE (eds.). 2003. Research at Hopland, 1951-2001: An Annotated Bibliography. UC Hopland Research and Extension Center. UC ANR Pub 104. 304 p.

Windberg LA, Knowlton FF. 1990. Relative vulnerability of coyotes to some capture procedures. Wildl Soc Bull 18(3):282-90. 